\title{
Three's a Crowd: The Translator-Author-Publisher and the Engineering of Girls of Riyadh for an Anglophone Readership ${ }^{i}$
}

\author{
Marilyn BOOTH \\ University of Oxford, UK
}

A frequent theme in postcolonial translation studies is the notion that it is the "first-world translator" who wields the power to shape the "third-world text." Rajaa Alsanea's Girls of Riyadh, an ostensibly "third-world text" published by Penguin, however differs in thoroughly consistent ways from the translation that I, the sole and ostensibly "first-world translator" submitted for publication. The fact that the "author-publisher" has been able to dismiss my reading of the text and replace it with theirs challenges this oft taken-for-granted notion and problematizes the process of translation, in which my role in the production of the English text was not only rejected by author and publisher but also minimized by the author's public statements. Between the presence of my name as "co-translator" on the title page, its absence in the Acknowledgments, and Alsanea's invocation of me as a desultory editor of her English lies a story of text circulation and commodification that, I argue, is best understood when one considers the apparatus of publicity and public image-making along with the less visible process of actually producing the text of a translation. In this story, what is "lost" happens less in the process of translation than it does in the process of publishing.

Banat al-Riyadh, from which Girls of Riyadh is translated, is rare if not alone among recent Arabic novels to capture large regional Arabophone audiences. Published in Beirut and London in 2005, it was an immediate sensation throughout the Arab world and generated anger and protest among some. Thus, for Western publishers it possesses a credibility (and profit potential) based not narrowly on marketability in Euro/American circuits but more broadly on 
popularity (and controversy) among its first, Arabophone, readers. If a novel has been phenomenally successful in Dubai, Egypt, and Tunisia, does it not beckon to a wider readership, one that can enjoy the novel and a sense of belonging to a global audience that includes Arabophone readers? Yet, moving into different reception areas, the best-seller novel is inevitably subject to editorial pressures speculating on how to guarantee similarly broad popularity (and sales) in the new host cultures. In this case, both globally marketed anglophone popular youth literature, especially "chick lit," and the Muslim feminine memoir not only presented a receptive potential readership for the novel but also put contextual pressure on the very style of the translated work.

In producing Girls of Riyadh from Banat al-Riyadh, I attempted a maximum amount of "literalist surrender" on the levels of semantic correspondence, register, juxtaposition, and stylistic play, though not on that of syntax. The result was not well received by the publisher and the author. Through the publisher's editorial staff, the author objected and requested that she be permitted to revise my translation without consulting me. The publisher concurred. What followed was a revised and published version of Girls of Riyadh that emphasizes immediate accessibility over "surrender to the text," similarity over difference, transparent equivalence over markedness of locality. Put simply, this version favors the "high readability" of chick lit over the punning satire, local embeddedness and intertextual play important to the power and novelty of this novel in Arabic. ${ }^{\mathrm{ii}}$ The author-publisher's version assimilates to cultural usages and clichés of North American and "mid-Atlantic" manners while minimizing a stylistic design that would privilege informal usage and local (Saudi) linguistic practices. It favors "a translation that produces the illusion of originality by effacing its translated status [...].The sheer familiarity of the translation, of its language and style, allows it to appear transparent and thereby pass for the 
original" (Venuti, 2004, p. 17). This translation mutes the suggestive ambiguity of chick lit as a genre that highlights romance yet in doing so addresses "many of the issues facing contemporary women ... issues of identity, of race and class, of femininity and feminism, of consumerism and self-image," as Suzanne Ferriss and Mallory Young have noted (2006, pp. 2-3). It removes local cultural references to pop and commodity culture, word play and even some trenchant narratorial asides. It is a neutralization of language and narrative voice that ungenders, homogenizes, and depoliticizes the text—precisely the opposite of my translatorial intentions.

\section{Ungendering}

On page one, the narrator, whose personality in the original engages the reader through her teasingly self-referential email introductions, and who highlights young women's modes of communication and experiences through her voice, launches her e-serial thus (in my translation):

Ladies, Girls, and Gentlemen: Get ready, because you are about to rendezvous with some of the most explosive scandals and noisiest, wildest all-night parties around. Your correspondent — and that's moi—is going to lead you into a world that's closer to you than any of your minds can imagine. It really exists. We all inhabit it but we are not really living it. After all, we all tend to believe in whatever we find easy to swallow and refuse to accept the rest. .ii $^{\mathrm{ii}}$

This opening passage introduces her irreverent style and very colloquial voice. The changed version reads as follows:

Ladies and Gentlemen: You are invited to join me in one of the most explosive scandals and noisiest, wildest all-night parties around. Your personal tour guideand that's moi-will reveal to you a new world, a world closer to you than you 
might imagine. We all live in this world but do not really experience it, seeing only what we can tolerate and ignoring the rest (Alsanea, 2007, p. 1).

This version sounds smoother. It constructs a more neutral narrator, one who does not play with the terminology of news media (as the novel does throughout), and who does not play on the edges of language(s). This narrator is not as bold a challenger to the language system or the gender system — as is the narrator of the original. Omitting "girls" (literally, "my young misses," anisati) from the list of addressees effaces a preeminent thematic focus and desired audience; it substitutes the disruptive, quirky "Ladies, girls, and gentlemen" with the clichéd "Ladies and gentlemen.", "Girls" or "young misses" (the Arabic usage indicates unmarried status but implies near-adulthood) are in fact the narrator's and novel's true concern. Girls on the cusp of adult responsibility and privilege, girls at a liminal stage in their lives, are its subjects and its world. At this theatrical opening moment, "girls" offers a beautiful contrast to what will become a dominant structural component of the novel and a highly entertaining conduit of critique: these emails are dually addressed. In almost every case, the narrator begins the chapter/email with a direct and defiant address to those who have written in during the week to challenge her portrayal of gender politics among young Saudis. These interlocutors, often addressed by their first names or internet aliases, are exclusively male until late in the novel, when the narrator mockingly celebrates the fact that a lone female has written to her. That her vocal critics are male is crucial; they become implicitly aligned with the story's male characters, who are mostly and willfully blind to local power dynamics of gendered relations, holding on to the meager privileges such dynamics offer, even as these young men are also victims of a system where power is based on generational as much as gender hierarchies. Those voicing anger or discomfort to the narrator are thus also implicitly victims who do not, or do not want to, 
recognize their victimhood (unlike the female characters, including the narrator). Yet they are the ones who "have voice." The point is made more painfully here by the address to "girls"-left out of the final English version-who remain mostly silent throughout but are represented forcefully by the narrator. Omitting "girls" in the edited translation and neutralizing the narrator's voice reduces the force of the narrator's act, her attempt to sassily voice the concerns of the silent. Indeed, this omission silences the very subjectivities that the book purports to highlight.

The published English version lessens the text's thoroughgoing emphasis on female experience and feminine perspectives. Arabic nouns are gender-specific, and so this emphasis is an obligatory one grammatically; here, grammatical gender markers underline the text's focus on feminine Saudi society, which is so often hidden away in discourse. I felt that specifying femaleness was most often appropriate to this thematic focus on society's, albeit economically privileged, female margins. The first chapter's email subject heading, for example, is taken from the first line of a poem by the popular Syrian poet Nizar Qabbani (1923-98), whose lyrical poems celebrate love and explore eroticism while attacking male privilege in Arab societies as detrimental to personal and public relations. I translated this line/heading, sa-aktubu 'an sadiqati (I will write of/about my friends [f. pl.]), as “I shall write of my friends who are female." The published version deletes "who are female" and thereby removes the gender particularity. When the poem is quoted later in the chapter, the published version changes my translation, above, to "I shall write of my girlfriends," losing the metrical and rhyme patterns I set up while deemphasizing the poem's political emphasis on the kinds of oppression visited solely on females. It instead highlights the personal and limited "my girlfriends" rather than the generalizing possibilities of "female," emphasized in my translation also by its placement at the end of the poetic line, a repeated refrain. In the case of this gender-marked word, grammatical 
gender, though obligatory, is not meaning-free. The content of the embedded poem, and its context — the novel—mark the term strongly with femaleness.

The daring playfulness of the narrator's voice, which I accented, sometimes compensating in one place for a necessary reduction of that tone in another, fades in the published version to a more circumspect voice, particularly concerning gendered behavior. For example, in chapter two:

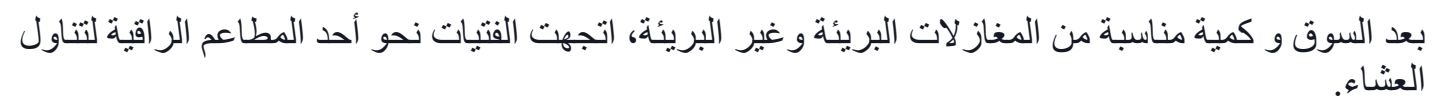

[After the mall/market and an appropriate amount of innocent and not-innocent flirtatious exchanges, the girls directed themselves toward one of the elegant restaurants for the taking/eating of dinner] (al-Sani', 2005, p. 25).

I translated the sentence as: "After the mall, and a pretty satisfying number of innocent flirtatious exchanges, plus a few (a very few) that were not so innocent, the girls set their sights on the smart restaurant they had picked out for dinner." In the published version, this has become simply: "The girls made their way toward the elegant Italian restaurant they had picked out for dinner" (Alsanea, 2007, p. 17). The narrator's teasing reference to "not-so-innocent" exchanges, which plays up the space for romantic and sensual negotiations, challenging the boundaries of social power, is deleted.

The force of the listserv name that graces every chapter is similarly minimized in the published version. Seereh wenfadha7et exemplifies the use of Latin characters to represent Arabic on the internet. It is an emerging language among wired Arab youth, spreading now from the internet to other forms of writing. The literal meaning of this cyber-transliteration is "A life story and it has been exposed"; the verb implies exposure of something disgraceful or shameful. ${ }^{\vee}$ 
The noun sira, or seereh in Internetspeak, is commonly used for "auto/biography," as opposed to mudhakkirat for "memoirs." But sira also signifies "conduct" or "way of life" and connotes the ultimate model of good conduct, the life of the Prophet Muhammad as narrated by later Muslim scholars in his sira (life story). What this novel "exposes" is not so much "shameful conduct" but the (scandal of) the rigors of comportment to which young people are held in Saudi society; what it also "exposes"- perhaps the bigger scandal—is that such rules of conduct have less to do with the guidance provided by Islam or the Prophet's life than with preserving a patriarchal, classdefined social hierarchy that buttresses the national status quo.

I translated Seereh wenfadha7et as "A Life Story . . . Laid Bare," to capture resonances of exposure and scandal, while hoping that "life story" might echo for some Anglophone Muslim readers the ultimate "life story" of the Prophet. To use the phrase "laid bare" also signals the narrator's consistently daring use of phrases that are just on the edge of appropriateness. The English Penguin version opts for "Memoirs Disclosed," which forecloses recognition of the intertextual Islamic echo and the socially disruptive intervention of the narrator, where "scandal" hovers between exposure of what is known but not said, and the very act of the young female narrator's public speech. The author's/publisher's choice to minimize these signal thematic effects of the Arabic at the very beginning of the text suggests a preference for a story and style that are conventional and easy to digest. The negative reviews, however, that greeted Girls of Riyadh may hint that muting the sly and skeptical gender politics of the Arabic original by substituting a bland and neutral language was a miscalculation on the part of the author and the editor. $^{\text {vi }}$ 


\section{Homogenization}

The Arabic text's explosive idiom arises in part from the juxtaposition of different languages that circulate and intertwine in today's Arabophone world. To the extent possible, I worked with the text's varying registers: from very colloquial to formal and "authoritative," and from Arabic to Saudi bourgeois English, represented hilariously when English loan words and phrases suddenly pop up, spelled phonetically in Arabic script according to prevailing urban Saudi bourgeois pronunciation. The novel's politics of language recognizes the heterogeneity of communication modes and their class specificities. Above all, it acknowledges and exploits the use of English by a young, savvy, globalized generation of Saudis. In the original, English words and phrases transliterated into Arabic convey how worldly these young characters are while also having the effect of localizing English, making it part of an Arabic elite globalized vernacular. Furthermore, these eruptive English phrases often highlight female appearance, physicality and consumption patterns, embedded in and arising from the globalization effects of transnational capitalism.

Thus, translation is part and parcel of this Arabic novel, as English words spill into local dialects, challenging any notion of a pure or boundaried language, which has long been and remains a politically sensitive topic among Arab and Muslim elites. The novel's linguistic weave reminds us that all texts are implicated in the politics of translation; this text represents within its languages a notion of the subject as necessarily a product of translations. Alsanea's Arabic style neatly conveys the spoken Arabization of English. I mimicked this feature through a resistant translation practice that would not smooth out the text but rather force the reader to consider (a local) English to be another language of and within the text. I italicized the novel's Arabenglish and spelled it phonetically according to the Arabic script. But in the revised version, my 
representation of Arabenglish is gone. Examples from a single page of the published translation: my transliteration $e w w w$-soo falguur becomes "Eww ... so vulgar"; tuu matsh is "too much"; and sheez soo kiyirvy ("she's so curvy") is deleted altogether (Alsanea, 2007, p. 7; al-Sani', 2005, pp. 16-17). One character speaks a line in standard English, which I conveyed as such, and that makes sense, for she has spent long periods in North America. But the interlingual flavor of the other girls' dialogue is "lost in translation"-or rather, in editing.

This "translated" Arabenglish is particularly the province of a young, with-it, feminine, privileged Saudi identity, an insight to which the Anglophone audience does not have access in the smooth monolingual language of the published translation. In Banat al-Riyadh, Arabenglish is an indigenous language, though (and importantly) one that by its presence highlights the invasion and saturation of consumption of North American and European cultural goods and concepts in Saudi Arabia and the cross-continental coming and going of Saudi subjects, in particular elite young women, who are cosmopolitan in their consumption habits, including the consumption-in-use of language, but are not free to enter or leave their locales of residence without the permission of men. The use of language points up this rupture but disappears in the translation authorized by Penguin. The language of the translation has become disconnected from the social fabric that the text draws upon and critiques through its satirical deployments of language as markers of character.

There is a danger that mimicking Arabenglish could buttress the Arab stereotyping so prevalent in North America, and I worried about this. Yet I decided that because the novel's Arabenglish was specific to younger characters, whose personalities are drawn sympathetically, this feature would not stereotype; rather, it would enrich their portraits as conversant across cultures and might even bring them closer to young Anglophone readers. It would also suggest 
that Saudi girls (of this particular socio-economic background) are not shut away linguistically, just as they are not uniformly shut away in their social lives. Indeed, they traverse the university campus, the mall and, for three of the characters, the streets of San Francisco, London and Chicago. Neutralizing the novel's multilingual cast flattens the text linguistically and thematically. If readers cannot tell that characters are using certain English phrases seamlessly and locally, embedded in their Arabic conversation, the globalized context is muted if not altogether lost. The possible dangers of exoticism in translation are outweighed by what the tactics of highlighting language mixing and a local English might achieve.

I tried also to convey the use of colloquial Arabic by maintaining a highly informal tone, though I was not able to capture the local politics of language represented by different regional Saudi dialects, a linguistic competition that would expose differences within the Saudi nation and internal stereotypes about different communities. In the published version, different registers are collapsed into each other far more than in my version. My colloquial English wordings are neutralized into a more standard English. ${ }^{\text {vii }}$ My retention of Arabic idioms, literally translated, is often deleted. The result does not convey the different strata of discourse which exist in meaningful tension in the Arabic novel, strongly shaping the characterization of various personae. The novel's polyphony of languages poses a critique of traditional fiction writing in Arabic by ignoring the usual constraints that push writers to adhere to a homogenized, nonvernacular language (even when writers use colloquial Arabics, these are often dominant, homogenized versions of local heteroglossia). Alsanea's use of Arabic in the novel shows how any sense of a bounded national "us" is predicated on contamination by "the other"; specifically, how Saudi national identity is crisscrossed, complicated, and formed by its situation within a globalized economy of linguistic use, where local Arabic dialects challenge the "unity in 
tradition" symbolized by formal Arabic, and where English saturates various Arabics. Yet, this is not a "global" English. It is a local language of fragments joining other fragments, in which the particular relationship of locals and globals is suppressed in a translation that does not allow heterogeneity of language to pebble or scar the smoothed surface of the published rendering.

\section{Depoliticizing}

With this effacement of radical language practices, the novel's (often hilarious) metafictional commentary on the Arabic literary canon and on pressures to write in conformity to it are mostly deleted. Perhaps it was felt that such a commentary was irrelevant to Anglophone readers; yet such commentary is what adds layers of signification to the novel as a work of cultural critique, constructing implicit parallels between the politics of writing and the politics of sociality in the culture. And why should Anglophone readers be denied access to the politics of Arabic cultural production? Narrow constraints on social behavior and alliance are inseparable from discursive constraints on the writer, the novel suggests; this parallel is absent in the shortened version sanctioned by author and publisher, and thereby one theme is entirely lost. Loss of that dimension makes this a less complex novel in English, and it bars Anglophone readers from considering the discursive politics of a part of the world that North American discursive politics are constructing and reconstructing daily. Furthermore, this loss of the metafictional dimension enhances a realist sleight of hand, focusing the reader on what happens rather than on how it happens, or the way discursive politics frame it.

Other omissions concern extended references to local knowledges and literary discourses through which gender politics are shaped, contested, and reworked. In chapter one, following the quotation of Qabbani's poem, the narrator addresses this poet who hovers over the text: 
You got it right, Nizar baby! Your tongue be praised, Qabbani, you 'weigher of things' as your name tells us! God bless you and miyy yoo rist in beese. Whoever first thought to call you 'the women's poet' got it right, too, and anyone who doesn’t like my saying so can go jump in a lake. ${ }^{\text {viii }}$

The narrator then refers to a widely known incident in the poet's family life, when his elder sister committed suicide because she was barred from marrying the man she loved, a tragedy that compelled Qabbani to ponder, and then to boldly contest, prevailing strictures on gender relations. He experienced tragedy again when his second wife, Iraqi-born Balqis al-Rawi, was killed in Beirut in 1982 by a bomb targeted at Iraq's embassy. Girls of Riyadh's feisty narrator addresses him thus (in my translation):

In love there's been no one before you and there will never be anyone after you, as the famous song goes, even if your compassion toward the S in SHE isn't thanks to a mutation in your male chromosomes but only due to your poor sister's suicide, the tragic end to a tragic love story. 'When love strikes, what it does conquer!' And oh the luck of the late Ms. Balqis, and oh what monkey luck we have, after youthere will never be anyone after you. 'Monkey luck' which people from Najd talk about, the luck of the qird, must be derived from the animal's constant jumping and leaping, which resembles luck in its continuous movement and stopping and crouching and waiting. Or perhaps, as some people claim, the expression comes from monkey-tick. But it seems, I'm sorry to say, that no woman among us will find her own Nizar until after she has finished off one of his sisters, so that the tale of beautiful love will no longer be a black and white film but will become a tale called 'Love in Prison.' Heart of mine, don't grieve. 
The published English version excises this passage. It is not easy to convey such local knowledges, but to avoid doing so undermines the novel's richness. It flattens the narrator as a character by silencing her knowledge of critical gender commentary in modern Arabic discourse. This passage highlights the Arabic novel's bold political intervention in gender politics through offering a suggestive parallel between historical events and the stories within the novel. It highlights tensions that many would rather forget, insisting that readers confront their possible roles in a conspiracy of silence around the lack of choices available to the young. It dismissesor disses - an ideology based on the idea that gender relations are built into human chromosomes rather than societally constructed. Mentioning Balqis, it invokes the context of war that —past and present—brutally shapes the lives and deaths of so many in the Arabic speaking region. It foreshadows the more "private" stories that the narrator will tell and also the way such stories are both suppressed and known. The stories of the sister and of Balqis thus act as cultural templates for the stories of the four girls, while quietly reminding readers and characters of the ultimate tragedies that result from attempted resistance to the implacable dominance of shared cultural practices and historically shaped communal tragedies. The passage is important thematically and structurally; to delete it is to depoliticize and de-gender the text. Ironically, Penguin's and Alsanea's practices as translator-editors have yielded a text that through omissions and changes becomes more complicit with the dominant ideology the novel satirizes.

Culturally specific references in the form of proper names (for example, of singers) are also omitted. These are becoming part of world culture and the reader should encounter them. To omit names of Arab singers while leaving in those of European designers alters the text's politics of cultural consumption. The point is that young Saudi bourgeois subjects are consuming both the local and the globalized. In the process they are having an impact on what counts as a 
cultural center in today's world, an insight that is deemphasized as the text loses its cultural specificities.

The examples above come for the most part from the first chapter, ${ }^{\mathrm{ix}}$ and I could continue in this vein throughout the entire novel. While I recognize that the author's input provided some needed cultural knowledge, and in places tightened my wordiness, most of the changes introduced into my English translation suggest a different ideology of translation, reducing cultural difference, homogenizing language to ease difference for the Anglophone reader, and minimizing daring cultural interventions and deadly serious humor. The preference for a smooth, cliche'-ridden language over the "unevenness" of colloquialism and punning perhaps indicates a desire to create a style — and a work — that is both less of a romp ("more serious?") and easier to read for an Anglophone reader. But a serious work need not have a serious tone, and the loss of the novel's satirical edge as well as its gender and cultural politics is a great loss indeed. If literary translations — crucial, given "the need to extend the American imagination [. . .] which regulates much of the world system"-require "thick and situated" understandings and rewritings (Appiah, 2004, pp. 399-400), this rendering of Girls of Riyadh does not fulfill its potential. The novel might be luckier in languages that the author cannot read or control. ${ }^{\mathrm{x}}$ Only then will the translation be allowed to thickly convey one language's wit and politics into another's.

\section{The Marketing of Islam via the Author's Visibility and Translator's Invisibility}

In complicated ways, market forces permeate the fabric of the new work that emerges from this translation-publishing process. As we know from decades of critical work on culture industries around the world, no published text is solely an act of disinterested aesthetic creation, impervious to material forces of book production and marketing. But literary translation is a 
particularly troublesome arena for competing pressures on the text, and the issues range far beyond the extent to which a translation may be said to represent the original, or precisely how it does so. There are issues of ownership, issues of the material bases of culture production. Also at issue is the translator's status as a piecework wage laborer whose access to the text is barred in the process of creating a particular kind of public image. In this process of creating a representation, who owns the text?

These are not easy issues; there is no "right answer" here. However, given the dominance of a rather static set of gender-saturated images in competing representations of Islam, Muslimness, and Arabness in today's global informational marketplace, it is important to ask how translational processes produce, contribute to, or undermine these dominant discourses (in a certain venue, at a certain moment) which continue to construct the homogenized figure of the Muslim Woman; to ask who controls these processes and what the effects might be. These questions are part of an ongoing conversation about the status of contemporary Arabic letters in translation, one that was perhaps publicly initiated by Edward Said's "Embargoed Literature" published in The Nation in 1990. As the language of Banat al-Riyadh is domesticated into its new Anglophone home, entitled Girls of Riyadh, through the erasure of many cultural and linguistic specificities, both the story in the text and the story of the text's controversial appearance in Arabic become more easily digested as ethnographic accounts where "difference" is easily assimilable to North American cultural and linguistic norms, and all of this is buttressed by the image of the author in the literary marketplace. This has the effect of further depoliticizing the narrative, taming the differences within, and — as a corollary of the author's status in the 
Euro/American marketplace as an authentic ethnographic subject—sidelining and discrediting the translator's role in producing the text. ${ }^{\mathrm{xi}}$ Whatever the author's own intention in rewriting the translation and dismissing the translator's role might have been, this produces a particular effect: it foregrounds the image of the authentic-but-cosmopolitan Muslim Woman whom the publisher and Anglophone audience appear to desire. This is an image of someone who is comfortable with English, able to write her own English text. Not only does this figure of the writer-heroine efface processes and effects of translation — and the status of literature and the author as globalized commodities — but it also silences questions about gender privilege and perhaps even Saudi national politics which arise in the Arabic text.

Effacing the translator-dismissing her reading of the text—-twines together several strong strands of contemporary "global" culture production, both generally and specifically concerning Arabic literature in English translation. There is the history of the marginal and muted status of the translator in capitalist societies, fortified by a prevalent ideology of individualism that upholds Romantic ideals of the author as lone genius. ${ }^{\text {xii }}$ A history too complex to narrate here, this yields a notion of translation as mechanical reproduction and the translator's role as ideally one of graceful self-effacement: a notion itself globalized despite translators having held different statuses in other times and places including Europe at earlier moments. These long-established concepts of the translator's role, shaped by humanist notions of authorship as privileged individuality, are not only hard to dispel, but are useful to the marketplace. They operate in tandem with the equally persistent view that literature (or some 
literatures) can act as a transparent siting of "the real" within the very real world of Frankfurtand New York-driven mass publishing.

This would explain why publishers are keen to get their hands on Saudi writing: if there is a single society that contemporary readers in the global North see as encapsulating the mystery of the "Islamic Orient," it is Saudi Arabia. Within that mystery, the mystery of mysteries remains the Arab Muslim woman, often homogenized and made to stand in for an entire society and history. A work purporting to tell the first-world Anglophone reader about the Middle East and Islam from the perspective and through the voice of that most mysterious and hyperrepresentative inhabitant and symbol of that world, a text authored by a Saudi woman and narrated by a young female Saudi character, gets to the veiled heart of Western fascinations. It is by now almost a cliché to note that the most intensely saturated stereotypical space of discourse when it comes to images of Arabs or of Islam is the space of gender. Not for the first time, the familiar nationalist trope of "Woman" as the repository of tradition and yet simultaneously as the primary imagery of an "imagined national modernity" acts as a globalized symbol of everything that is supposedly wrong with the Arab/Islamic/Middle Eastern Other and of everything that needs to be made right. Although Girls of Riyadh is fiction, its market potential is based partly on this (mis)conception of representation and the recent popularity and iconography of autobiographical writing by women self-identified as Muslim, Arab, Middle Eastern, etc. Its author's celebrity status hinges on North Americans' and Europeans' fascination with "unveiling" the Muslim female author who attests to feminine experience. It seems no accident that profiles of Alsanea shortly after the English translation came out emphasized her own life experience and assumed the documentary value of her book, collapsing author and narrator into one. .iii $^{\text {ii }}$ 


\section{Conclusion}

It is often assumed among audiences both in the West and in the Arab world that we translators have a modicum of power to choose which works - here, of Arabic literature-will emerge on the world market and how they are translated, and in informal settings with writers and readers we are often criticized for making bad choices of texts to translate. This does speak to the relatively powerless position of most Arab fiction writers (excluding an internationally famous few). Yet it ignores other, often more powerful, players: publishers, editors, agents - and occasionally authors, even those who hail from the global South.

For me, as translator, embeddedness in certain narratives — of US state and non-state engagement with Arab societies, of prevailing and homogenizing images of "the Muslim woman," and of cultural expression in Muslim-majority societies (images in which censorship, "tradition," and lack of creative output dominate) — spurred my resistance to a translation practice that might support those homogenizing images. Alsanea, the author, might be embedded in some of the same narratives, but her situatedness is different and perhaps raised a different set of concerns governing her translational preferences. The concept of enframing-reframing developed by translation theorist Mona Baker (2007) is useful here. In Baker's terms, Alsanea made different choices which "reframed" the translation, including self-presentation to journalists, a paratextual envelope that also shaped how readers would come to the text. For both of us, the reception context for Girls of Riyadh was heavily determined by a discursive context in which "the Muslim woman" as a covered figure stands in for "Islam." But how we handled that inescapable framing diverged. It may be that because Alsanea was able to present herself as representing her society, offering a personal narrative to mediate some readers' consumption of 
her novel, she did not feel a need to emphasize localities and differences in the text as I did.

Alsanea's "re-narration” (Baker's concept) of my "re-narration” of her Arabic narrative suggests the power of situatedness in acts of translation.

For Baker, and based on social movements theory, framing may consist of "deliberate discursive moves designed to anticipate and guide others' interpretation" of events (156; emphasis in the original). Alsanea and her editors reframed the novel in English by altering my translation: they reduced the available feminist narrative that I had played up with my choices. I am not calling upon, or assessing, a notion of translational accuracy here (a futile task in any case), but I would argue that my translation remains closer to the original Arabic in reproducing (not omitting) lexica, modes of address, and genres of cultural repartee. ${ }^{\text {xiv }}$ It does not, for instance, efface the available narrative of class and globalization that emerges in the Arabic through the use of Arabenglish. Such choices, Baker argues, are not random but are "embedded in and contribut[e] to the elaboration of concrete political reality" (p.158). Of course, my writing of this article and others, and my widely circulated letter to the editor of the Times Literary Supplement (2007) in response to its review of the translation, are also attempts to reframe the translation.

The translator is a pivot point in intercultural conversations, a broker of discourses. Translators usually possess considerable cultural capital, as educated bilingual or multilingual citizens of the world and often employees of elite educational institutions. Yet the translator is also a wage laborer in the transnational circuitry of representations, one who most often does not own the rights to her or his own work. Once a text is released into the public sphere, of course, circulating as a commodity while representing the democratic claims of intercultural 
conversation, it is owned above all by the readers who interpret it. But readers need to remain vigilant about the highly mediated processes and contestations that lie behind the word on the page. The transformation of Banat al-Riyadh into Girls of Riyadh-with a marketing and publicity apparatus encouraging readers to regard the author as translator and spokesperson, and the Americanization and de-politicization of the text in translation-suggests just how diff erentially local the transnational marketplace of literary production is.

The task, for me, was to "bring the reader to the work"- to insist on an English rendering that would defamiliarize the text, draw readers into its Arabic discursive world, complicate Orientalist desires, raise questions about the extent to which it could be read easily as a transplanted Sex and the City, and obligate audiences to take account of its political critique. For Alsanea and her editors, it appears, the task was to "bring the work to the reader" - to play up pop-lit affinities (whatever the author's longer-term ambitions might be to transcend the popfiction rubric in her own career), minimize its gender politics, and give it an easy popularity on the North American street which allows readers to comfortably consume the familiar Otherness of this story set in Saudi Arabia_-as well as to sell copies.

\section{Works Cited}

Alsanea, R. (2007). Girls of Riyadh (R. Alsanea \& M. Booth, Trans.). New York: The Penguin Press; London: Fig Tree.

Al-Sani', R. (2005). Banat al-Riyadh. London: Saqi.

Al-Sani‘, R. A. (2005). Banat al-Riyadh: Riwaya. Beirut: Dar al-Saqi.

Appiah, K. A. (2004). Thick translation. In L. Venuti (Ed.). The Translation Studies Reader (pp. 389-401). London: Routledge. 
Baker, M. (2007). Reframing Conflict in Translation. Social Semiotics, 17 (2), 151-69.

Booth, M. (2008). Translator v. Author (2007): Girls of Riyadh Go to New York. Translation Studies, 1(2), 197-211.

Booth, M. (2010). "The Muslim Woman" as Celebrity Author and the Politics of Translating Arabic: Girls of Riyadh Go on the Road. Journal of Middle East Women's Studies 6 (3), 149182. DOI: $10.1353 / \mathrm{jmw} .2010 .0008$.

Ferriss, S. and Young M. (2006). Introduction. In S. Ferriss and M. Young (Eds.). Chick Lit: The New Woman's Fiction (pp. 1-13). New York: Routledge.

Koning, C. (2007). Girls of Riyadh. The Times, July 14.

Mazza, Cris. Who's Laughing Now? A Short History of Chick Lit and the Perversion of a Genre. In S. Ferriss and M. Young (Eds.). Chick Lit: The New Woman's Fiction (pp. 17-28). New York: Routledge.

Said, E. (1990). Embargoed literature. The Nation, September 17.

Venuti, L. (2004). Introduction to "Foundational statements." In L. Venuti (Ed.). The Translation Studies Reader (pp. 1-9). London: Routledge.

i This article consists of amalgamated text from Booth (2008) and Booth (2010), with permission from both publishers.

ii Chick-lit "high readability" is Stephanie Harzewski’s formulation (Mazza, 2006, p. 25).

iii All translations not followed by a citation are from my manuscript. Because I am mostly comparing translations, I give the Arabic only when crucial.

${ }^{\text {iv }}$ As customary in Arabic, literally: My ladies, my young misses, my gentlemen.

${ }^{v}$ Al-Ghadeer 2006 explains the phrase's relationship to a Lebanese TV show title.

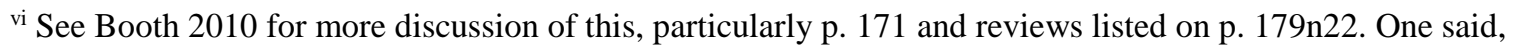
"Clunking phrases and clichéd images are found on every page" (Koning, 2007). Given space enough, it would not be difficult to demonstrate that many of the clichés are a product of the editorial process's translation choices rather than being present in the Arabic text (or in my unpublished translation); at times, moreover, clichés are used precisely to point up stereotypes, a strategy I endeavoured to convey but which the editor and author apparently did not wish to maintain. 
vii Example: for my "it's the hideous ones who are flying off the shelves these days" is substituted "the ugly ones seem to be in demand these days" (Alsanea, 2007, p. 5).

viii Published version: "Right you are, Nizar baby! Your tongue be praised, God bless you and may you rest in peace. Truth be told, though you are a man, you are indeed 'the woman's poet' and if anyone doesn't like my saying so they can go drink from the sea" (Alsanea, 2007, p. 3). "Drink from the sea" translates the Arabic idiom literally and on reflection, I prefer it to my use of an American idiom. The poet's name, Qabbani, means "weighmaster," an important post in premodern Arab societies which went beyond weighing to overseeing aspects of public social negotiation. I chose to highlight this double meaning.

ix Other changes include adding cultural information as footnotes rather than within the text, blended into its chatty tone; deleting puns; deleting my use of present tense, which draws readers into the scene's immediacy (the published version puts the entire narrative in past tense). I often used terms with multiple resonances, now changed to words with narrower meanings.

${ }^{\mathrm{x}}$ As my conversations with the Finnish translator have suggested! But the multiplier effects of secondary translation must be considered: often, works of Arabic literature, like works from other so-called difficult languages, are translated into other tongues from the English or French translation rather than from the Arabic.

${ }^{x i}$ For an elaboration of these points see Booth, 2010.

xii I do not mean to suggest that historically translators have been "invisible" only under capitalist structures, but the intersection of ideologies of individualism and modes of capitalist production has fostered this view of translation; under other regimes of culture production, translators have sometimes been regarded quite differently. See Venuti, 1995.

xiii See Booth, 2010.

${ }^{\text {xiv }}$ For examples, see Booth, 2008. 